\title{
Article \\ Structural Behavior of Prefabricated Ecological Grid Retaining Walls and Application in a Highway in China
}

\author{
Xinquan Wang ${ }^{1}$, Cong Zhu ${ }^{2}$, Hongguo Diao ${ }^{1, * \mathbb{C}}$ and Yingjie Ning ${ }^{3}$ \\ 1 Department of Civil Engineering, Zhejiang University City College, Hangzhou 310015, China; \\ wangxq@zucc.edu.cn \\ 2 School of Civil Engineering, Shaoxing University, Shaoxing 312000, China; zc691221@163.com \\ 3 Zhejiang Jiaogong Group Co. Ltd., Hangzhou 310000, China; ningyingjie@zjjtgc.com \\ * Correspondence: diaohg@zucc.edu.cn
}

check for updates

Citation: Wang, X.; Zhu, C.; Diao, H.; Ning, Y. Structural Behavior of Prefabricated Ecological Grid Retaining Walls and Application in a Highway in China. Symmetry 2021, 13, 746. https://doi.org/10.3390/ sym 13050746

Academic Editor: Raffaele Barretta

Received: 25 March 2021

Accepted: 22 April 2021

Published: 24 April 2021

Publisher's Note: MDPI stays neutral with regard to jurisdictional claims in published maps and institutional affiliations.

Copyright: (c) 2021 by the authors. Licensee MDPI, Basel, Switzerland. This article is an open access article distributed under the terms and conditions of the Creative Commons Attribution (CC BY) license (https:// creativecommons.org/licenses/by/ $4.0 /)$.

\begin{abstract}
The retaining wall is a common slope protection structure. To tackle the current lack of sustainable and highly prefabricated retaining walls, an environmentally friendly prefabricated ecological grid retaining wall with high construction efficiency has been developed. Due to the asymmetrical condition of the project considered in this paper, the designed prefabricated ecological grid retaining wall was divided into the excavation section and the filling section. By utilizing the ABAQUS finite element software, the stress and deformation characteristics of the retaining wall columns, soil, anchor rods, and inclined shelves in an excavation section, and the force and deformation relationships of the columns, rivets, and inclined shelves in three working conditions in a filling section were studied. The study results imply that the anchor rods may affect the columns in the excavation section and the stress at the column back changes in an M-shape with height. Moreover, the peak appears at the contact point between the column and the anchor rod. The displacement of the column increases slowly along with the height, and the column rotates at its bottom. In the excavation section, the stress of the anchor rod undergoes a change at the junction of the structure. The inclined shelf is an open structure and is very different from the retaining plate structure of traditional pile-slab retaining walls. Its stress distribution follows a repeated U-shaped curve, which is inconsistent with the trend of the traditional soil arching effect between piles, which increases first and then decreases. For the retaining wall structure in the filling section, the numerical simulated vehicle load gives essentially consistent results with the effects of the equivalent filling on the concrete column.
\end{abstract}

Keywords: prefabricated retaining wall; ecological retaining wall; shutter insert plate; finite element analysis

\section{Introduction}

The retaining wall is a common slope-supporting structure. The degree of prefabrication, greening capacity, and drainage capacity of retaining walls play a significant role in the construction efficiency and environmental friendliness. It should be noted that the traditional pile-slab retaining wall has a low degree of prefabrication, as most of it is cast in situ. When it is applied for soil slopes, it is necessary to drill cast in situ columns after the completion of construction. Meanwhile, anchor rods and other structures are driven near the soil joint force points to limit their rotation, which could destroy the original integrity of the columns. As a result of adopting a closed plate structure, problems related to poor drainage performance and weak sustainability have emerged. Moreover, pile structures are mostly solid rectangular parallelepiped columns, which do not use concrete in the most efficient way and increase engineering costs. Therefore, structural improvements are necessary.

Retaining wall structures have various forms, of which one particular type is the gravity retaining wall [1]. It has the advantages of using convenient materials, having 
a thick and stable structure, and simple construction technology. However, its overall cost is high, construction speed is slow, it requires high foundation capacity, exhibits poor water permeability, and has an unaesthetic appearance. Stone-cage retaining walls [2] have good water permeability and do not require high foundation capacity, but their construction quality is difficult to control. Furthermore, they occupy a large land area after greening. Reinforced-earth retaining walls [3,4] have the advantages of strong deformation resistance and low cost. However, their construction quality is difficult to control and they cannot support steep slopes during greening. Cantilever/buttress retaining walls [5,6], or similar, require low foundation bearing capacity, which preserves the land. However, their construction is much more complicated and of low efficiency and their ecological performance could be poor.

In an investigation of an excavation section similar to this project, the limit equilibrium method and two-dimensional numerical simulations were employed by Rabie [7] to study the failure modes of soil-nail walls and their structural behavior. It was concluded that the traditional limit equilibrium method cannot be utilized alone in the design for this type of retaining wall, and therefore numerical methods and other means are required to be applied as well. By comparing Kötter's equation with the experimental results, Deshmukh et al. [8] found that their proposed calculation method can better predict the case where the burial depth ratio of anchor rods is less than 8 in compact and cohesive soil. Yuan et al. [9] studied the soil-nail retaining wall through practical engineering and summarized the construction highlights. They concluded that this type of retaining wall is suitable for use close to residential buildings and can be applied on smaller sites. With regard to the related research on filling sections, Day et al. [10] simplified the numerical model of the pile-slab retaining wall, and obtained the distribution of pile, slab, and soil stresses. Farhat et al. [11] utilized beam theory and finite element analysis to optimize a fully prefabricated buttress retaining wall. Based on full-scale tests and finite element analysis, the bearing capacity characteristics of each structure of the system were obtained. Subsequently, it was concluded that the rivets play a significant role in the connection between the retaining wall and the bottom plate. Ortiz et al. [6] simulated the impact of earthquakes on the cantilever retaining wall using centrifuge testing. Subsequently, they obtained an empirical curve of the upper limit response of the retaining wall and the seismic characteristics of the structure. Derucher et al. [5] discussed the design method of the cantilever retaining wall, as well as the method for calculating the earth and the overload pressures. By comparing the calculation results with a computer program, the latter was improved.

In this project, the structure investigated is an improved pile-slab retaining wall. In particular, the pile-slab retaining wall has the advantages of small disturbance to the soil behind the pile, large anti-sliding ability, and flexible pile placement. Specifically, the stiffness difference between the piles and the slabs is large for this type of retaining wall system. Consequently, it causes uneven displacement of the soil and results in a soil arching effect [12]. By applying the trap-door tests, Terzaghi [13] proved the existence of the soil arching effect. As a result of the soil arching effect, the earth pressure is transmitted to the pile through the arch toe of the soil and the baffle only bears the earth pressure, which has a shape similar to a cone. In other words, the earth pressure of the baffle is relatively small [14]. So far, existing studies have discussed the optimal pile spacing and pile body forces $[12,15,16]$, but there are relatively few investigations on the shape of structural members of the pile-slab walls.

By utilizing ABAQUS, Zevgolis [17] analyzed the bearing capacity characteristics and soil stress of a retaining wall under the vehicle load at various positions. The design and response mechanism of retaining walls considering dynamic loads are further discussed in recent research $[18,19]$.

Due to the asymmetrical condition of the project considered in this paper, the designed prefabricated ecological grid retaining wall was divided into the excavation section and the filling section. The finite element simulations of the prefabricated ecological grid retaining 
wall in the excavation section are conducted to verify the safety and reliability of the structure for the particular project of Provincial Highway 03 in Zhejiang Province, China. In addition, the design of the prefabricated ecological grid retaining wall in the filling section is studied and vehicular load model simulations are utilized to compare with the equivalent soil thickness calculation method of an existing standard [20].

\section{Project Overview}

The width of the roadbed in this project is $26 \mathrm{~m}$, the designed speed is $80 \mathrm{~km} / \mathrm{h}$, and there are four lanes in both directions. The starting point of the project is at the intersection of Zhejiang Provincial Highway 03 Dongfu Line and Hangjinqu-Linpu Expressway connecting line, passing through Linpu Town and Jiayuan Town, and ending at the junction of Xiaoshan and Zhuji Diankou Town. The entire line is about $16 \mathrm{~km}$ long. Since the Tangmei line needs to remain open to traffic, 16 slopes and 2 small slopes that were caused by this widening need to be re-designed for protection, to improve traffic capacity, and to improve driving comfort. Due to the tight schedule for the widening and reconstruction of the 03 Provincial Highway Dongfu Line, the original design of the slope protection scheme was deemed unsuitable for implementation. Thus, a prefabricated ecological grid retaining wall was developed to ensure the smooth progress of the project.

Considering the complex terrain factors, the side slope above the designed roadbed of highway should be excavated, while that below the roadbed needs to be filled, in order to ensure the safety and stability of roadbed and side slope. Generally, the loads of the retaining wall at its two sides are different (i.e., asymmetrical loads), which is contradictory to the assumption of the symmetry condition. Designing the retaining wall by conventional methods may reduce the safety factor when the smaller load is selected or lead to conservative and wasteful results when the larger load is selected [21-23]. Therefore, the prefabricated ecological grid retaining wall should be rationally designed in order to ensure the safety of the structure. As a result, the prefabricated ecological grid retaining wall was divided into two sections, the excavation section and the filling section, as shown in Figure 1. In the excavation section, the column-slab anchor wall was implemented as the slope protection structure, while in the filling section, the assembled cantilever retaining wall was adopted.

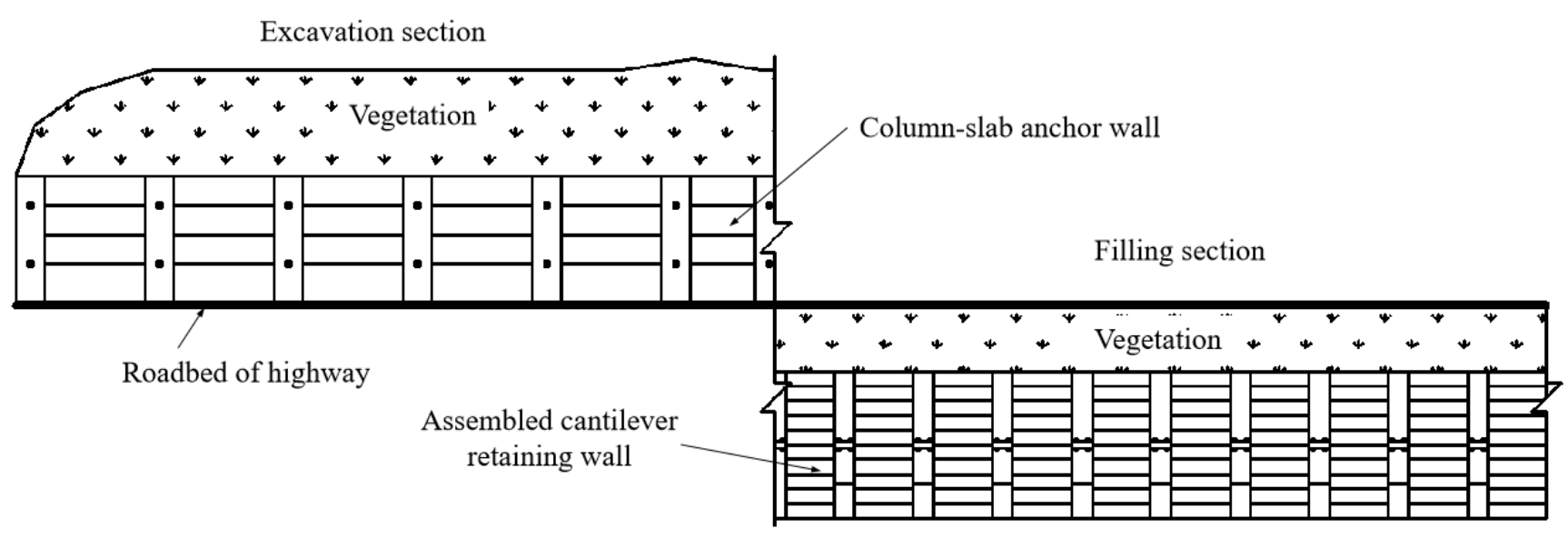

Figure 1. Schematic diagram of the prefabricated ecological grid retaining wall in the excavation section and the filling section.

It should be noted that the side slope surface is mostly tuff, and the rock bedding is not obvious. Straight and parallel horizontal bedding of some side slopes has been developed, with good continuity and parallel to the layers, and thickness ranges from $3 \mathrm{~cm}$ to $50 \mathrm{~cm}$. 


\subsection{Excavation Section Overview}

It can be observed from Figure 2 that the prefabricated ecological grid retaining wall consists of columns, inclined shelves, and anchor rods. Moreover, the lateral positioning bosses of adjacent columns are utilized as inclined shelf racks, which provide inclined shelf support. Furthermore, multi-layer prefabricated slabs are inclined toward the side slope, and grid grooves are formed between layers. The cross-section of the column is rectangular and the columns are fixed by rods anchored in the slope. The inclined shelf is standardized and prefabricated off-site. Substantially, vegetation can be realized by combining it with the column.

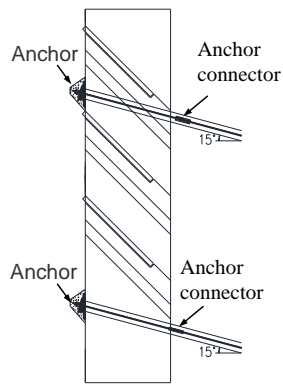

(a)

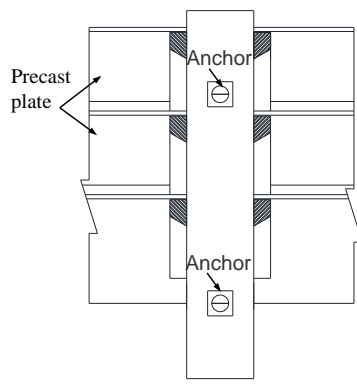

(b)

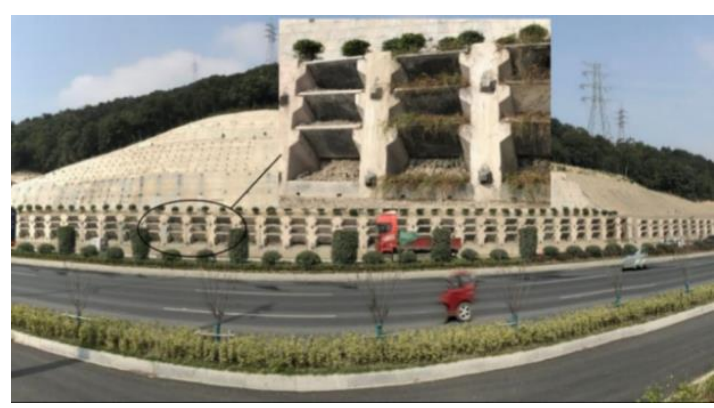

(c)

Figure 2. Prefabricated column-slab anchor rod retaining wall in the excavation section: (a) Cross-section; (b) Plan view; (c) As-built photograph.

Compared to the traditional column-slab retaining wall, the column has a new limit boss, which includes a positioning support and a stopper. In particular, the stopper is formed on the side of the positioning support, at $45^{\circ}$, and facing the slope to limit the prefabricated slab. The multi-layer prefabricated slab is inclined toward the slope and a grid groove is formed. It should be noted that a grid space could be created on the slope surface by filling the louver-shaped grille grooves. The surface of the high and steep slopes can be greened by planting small shrubs and climbing vines while hiding the masonry body. Moreover, the cross-section of the column is fixed by a rod anchored into the slope. The locking anchor rod on the column is the reserved exposed end of the rod temporarily anchored on the slope and the two are connected through an anchor rod connector.

\subsection{Filling Section Overview}

Figure $3 a, b$ shows the cross-section and plan view of the assembled cantilever retaining wall in the filling section. The columns are composed of the upper and lower columns and are connected by rivets, which is different compared to other column-slab retaining walls. In particular, the retaining wall is $5 \mathrm{~m}$ high in the actual project (the upper column is $2.5 \mathrm{~m}$ high, and the lower column is $2.5 \mathrm{~m}$ high) and the columns are at a net distance of $2 \mathrm{~m}$ and support prefabricated inclined shelves, while the upper part of the inclined shelves is filled with soil for greening. 3D Studio Max is utilized for rendering as the filling section has not yet been constructed, which is shown in Figure 3c. 


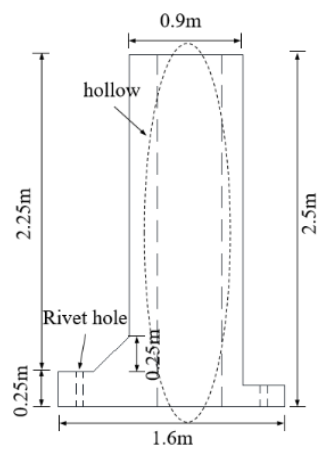

(a)

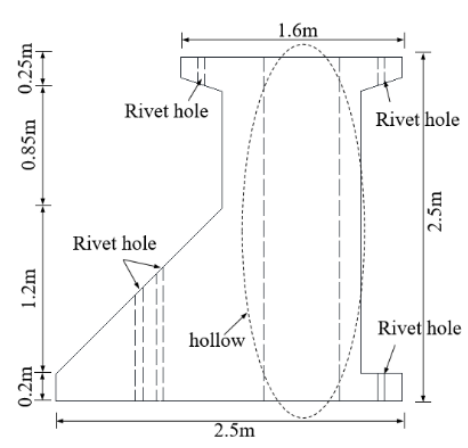

(b)

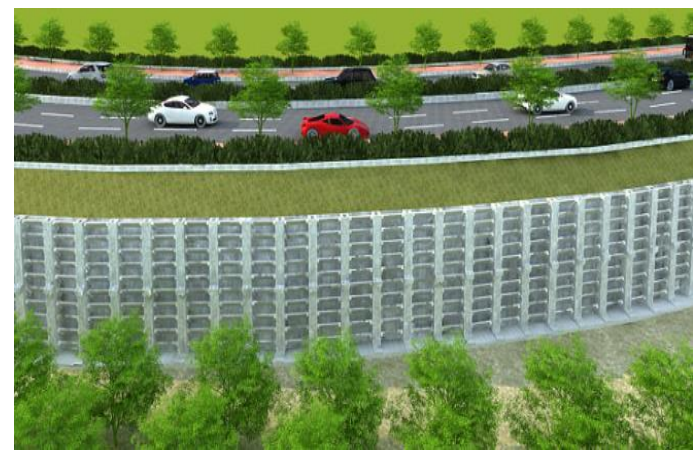

(c)

Figure 3. Assembled cantilever retaining wall in the filling section: (a) Cross-section; (b) Plan view; (c) Rendering drawing.

\section{Structural Behavior of Retaining Walls in Excavation Section}

\subsection{Numerical Model}

\subsubsection{Model Formulation}

In this project, the height of the retaining wall column is $4.4 \mathrm{~m}$, the net distance between columns is $4 \mathrm{~m}$, the columns support inclined shelves between them, the upper part of the inclined shelves is filled with concrete leveling layer, and the columns and soil are fixed by anchor rods. In order to avoid the drilling holes during the construction of the retaining wall, the PVC pipes for placing the anchor rods are embedded in the column during prefabrication. The inclined shelves of the retaining wall can be planted with vegetation to improve the landscape. Compared with the traditional pile plate retaining wall, the retaining walls in this paper can not only improve the driving comfort, but it also improves the drainage capacity. Because of its high prefabrication, the construction period of this kind of retaining wall can be substantially shortened, so as to reduce the cost.

The three-dimensional finite element model of the prefabricated ecological grid retaining wall is shown in Figure $4 \mathrm{a}$. The three-sides constrained by the soil are assumed to be a roller bearing type, and the structured meshing method is utilized in this model. Moreover, columns, soil, anchor rods, inclined shelves, and leveling layers all use eightnode hexahedral elements (C3D8). The contact surface of the inclined shelves and columns adopts the hard contact model for the normal direction, and the penalty method is utilized for tangential contact. In addition, the internal reinforcement cage of the columns and the internal reinforcement mesh of the inclined insert plates are modeled with one-dimensional truss elements, embedded in the columns and the insert plates. The anchor rods are divided into two sections, which are respectively embedded in the column and the soil. There are two anchor rods inside each column, where the upper part of the column has a $9 \mathrm{~m}$ anchor rod (Anchor Rod 1 ) at $0.8 h$ ( $h$ represents the height of the column), and the lower part has a $6 \mathrm{~m}$ anchor rod (Anchor Rod 2) at $0.14 h$.

The model has a total of 74,188 nodes and 74,944 C3D8 finite elements. The column side with the largest stress is the soil side, and the column is divided laterally into three parts. Subsequently, a total of four groups of nodes are obtained. Since the overall model has a symmetrical structure, four groups of nodes (Node Group 1 and Node Group 2) are taken for analysis, which is demonstrated in Figure $4 \mathrm{~b}$. It should be noted that Node Group 1 refers to the node set of the column back at the junction with the soil, while Node Group 2 means the node set of the column corner at the junction with the soil. 


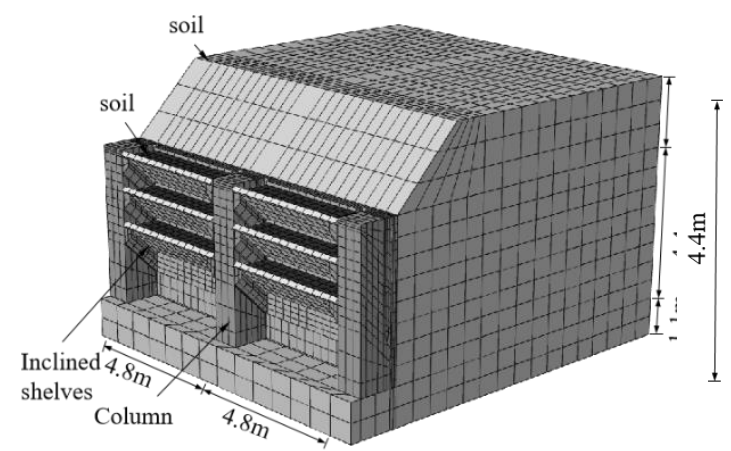

(a)

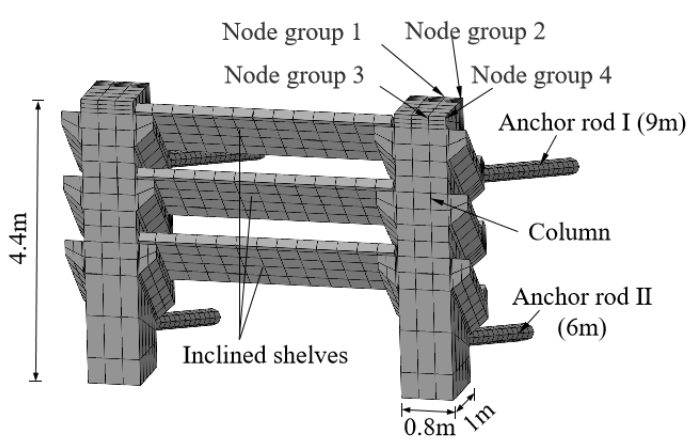

(b)

Figure 4. Assembled ecological grid retaining wall model: (a) Overall model; (b) Retaining wall structure.

\subsubsection{Parameter Selection}

For the anchor rods and steel bars, the elastic constitutive model is applied, the material is assumed to be isotropic, and the von Mises (the fourth theory of strength) analysis is conducted under the von Mises yield condition. The concrete columns in the excavation section were simulated using the concrete dispersion cracking constitutive model. In recent research [24-27], the concrete dispersion cracking model was compared to the plastic damage model in ABAQUS, and it was concluded that the dispersion cracking model is suitable for monotonically loaded structures, while the damage model is suitable for cyclically loaded structures. In this paper, the maximum principal stress is utilized to analyze the stress distribution in concrete. The maximum principal stress theory refers to the maximum tensile stress in the structure reaching the ultimate stress under the unidirectional stress state, when the material undergoes brittle fracture, i.e., brittle failure occurs. The soil is regarded as an ideal elastoplastic body, which obeys the Mohr-Coulomb failure criterion. Table 1 lists the ABAQUS input parameters and the design tensile and compressive strength values [28].

Table 1. ABAQUS input parameters and design values.

\begin{tabular}{cccc}
\hline & Filling Soil & Concrete (C30) & $\begin{array}{c}\text { Anchor Rods and Steel } \\
\text { Cages (HRB400) }\end{array}$ \\
\hline Young's modulus $(\mathrm{MPa})$ & 25 & 30,000 & 200,000 \\
Poisson's ratio & 0.3 & 0.2 & 0.3 \\
Cohesion $(\mathrm{kPa})$ & 20 & - & - \\
Internal friction angle $\left(^{\circ}\right)$ & 22 & - & 7800 \\
Density $\left(\mathrm{kg} / \mathrm{m}^{3}\right)$ & 1800 & 2700 & 360 \\
Tensile design strength $(\mathrm{MPa})$ & - & 1.43 & 360 \\
Compressive design & - & 14.3 & \\
strength $(\mathrm{MPa})$ & & & \\
\hline
\end{tabular}

\subsection{Component Stress Analysis}

Rabie [7] applied the limit equilibrium method and two-dimensional finite element model to simulate an anchor retaining wall. However, it was found that it may not be suitable to use the limit equilibrium design method alone for the combined anchor retaining walls. Thus, the finite element simulation is necessarily required. In this paper, ABAQUS is utilized to carry out finite element simulations for the retaining wall in the excavation section, its structural stress characteristics are analyzed, and the safety of the retaining wall is validated. 


\subsubsection{Stress Analysis of Columns}

The change in stress along the column height is shown in Figure 5. As the column is constrained by the anchor rod, the stress of the column changes slightly with the height at 0-0.7h (i.e., 0-3.1 m). Near the point where the Anchor Rod 2 passes through the column (about $0.14 h$, i.e., $0.62 \mathrm{~m}$ ), the stress increases slightly due to the temporary lack of anchor rod constraint, reaching a peak value of $0.42 \mathrm{MPa}$. Moving up, one enters the influence zone of Anchor Rod 1 again and the stress gradually decreases. Above the crossing point of Anchor Rod 1 (approximately 0.7h, i.e., $3.1 \mathrm{~m}$ ), a cantilever structure is formed due to the complete loss of anchor rod constraint. The stress rapidly increases to a peak value of 1.303 MPa and then it drops. The dashed line shows the specification limit in Table 1. The stress values in the structure do not exceed the specification limit in this working condition and the structure is safe.
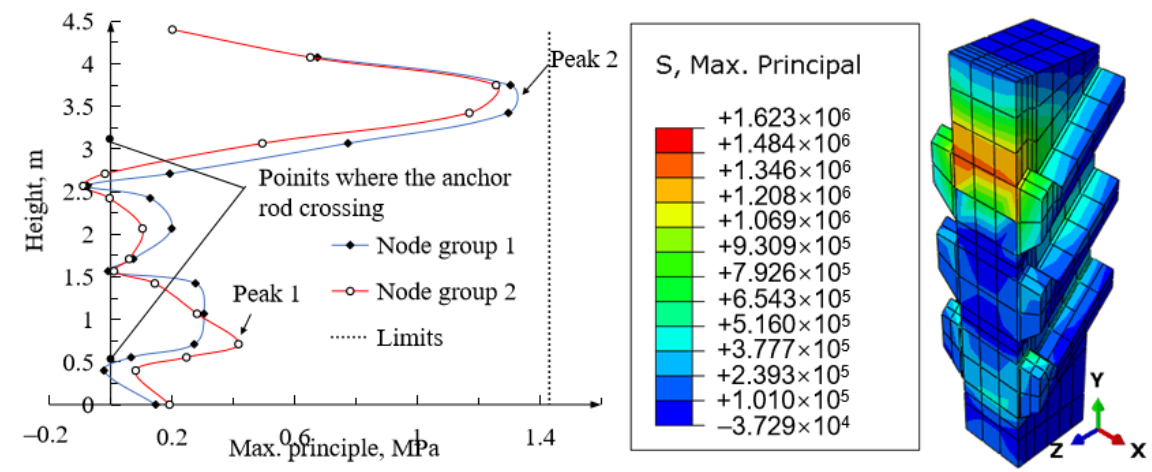

Figure 5. Stress distribution at column back.

The anti-overturning ability of the column could significantly affect the safety of the slope, so its lateral displacement needs to be analyzed. The change in lateral movement of the column along its height is shown in Figure 6. The side displacement of the column is small as the anchor rod applies a greater constraint on the column to restrict its outward inclination. It can be observed that the overall displacement trend of the column gradually increases with height. Due to the constraint of Anchor Rod 2, the displacement of the column top is only $2.5 \%$ larger than the displacement value of the anchor head for Anchor Rod 1. On the other hand, the column bottom is restricted by the concrete slab. The displacement is approximately zero and the column can be approximately considered as rotating around its bottom.
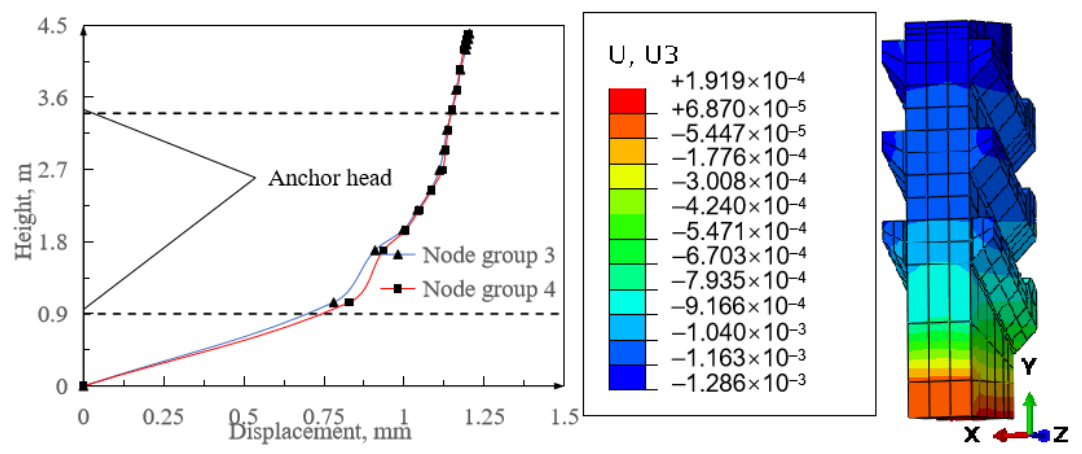

Figure 6. Column displacement curve.

\subsubsection{Stress Analysis of Inclined Shelves}

The stress and displacement between the inclined shelves are therefore taken as the stress evaluation criteria of the inclined shelf, and the inclined shelf is sliced to show only the stress nephogram slice of the middle of the board. 
As demonstrated by the basic principles of mechanics of materials, the first strength criterion is suitable to describe the structural behavior of the brittle fracture of materials, such as concrete. The maximum displacement and principal stress of the proposed prefabricated ecological grid retaining wall mainly occurs in the inclined shelves. As a result, the numerical results are presented in terms of the stress and displacement distributions in the inclined shelves, as shown in Figures 7 and 8.
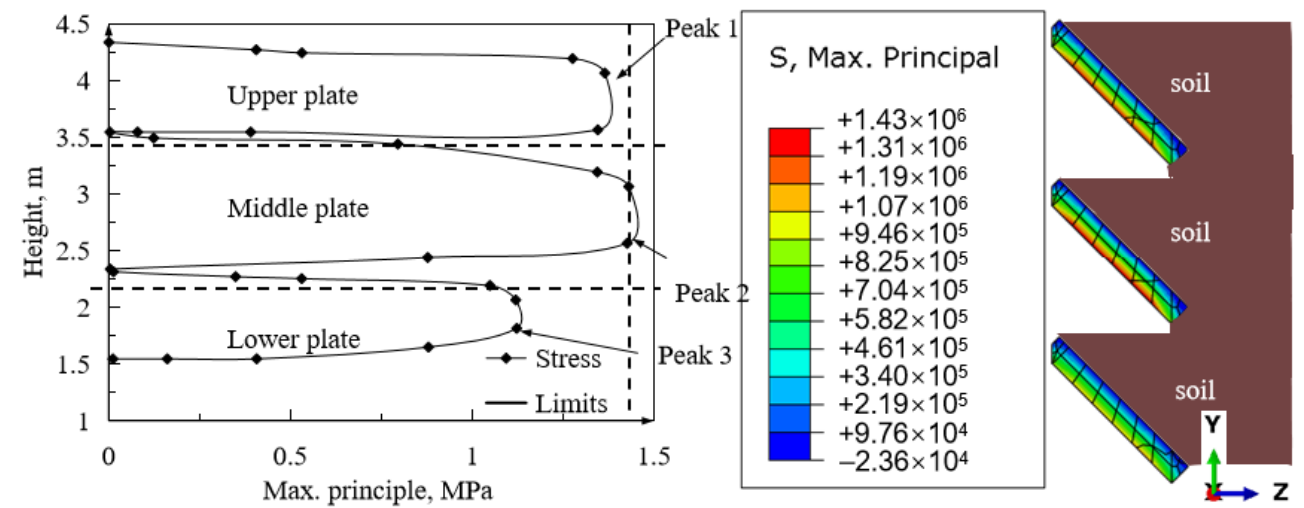

Figure 7. Maximum principal stress curve of inclined shelf with height.
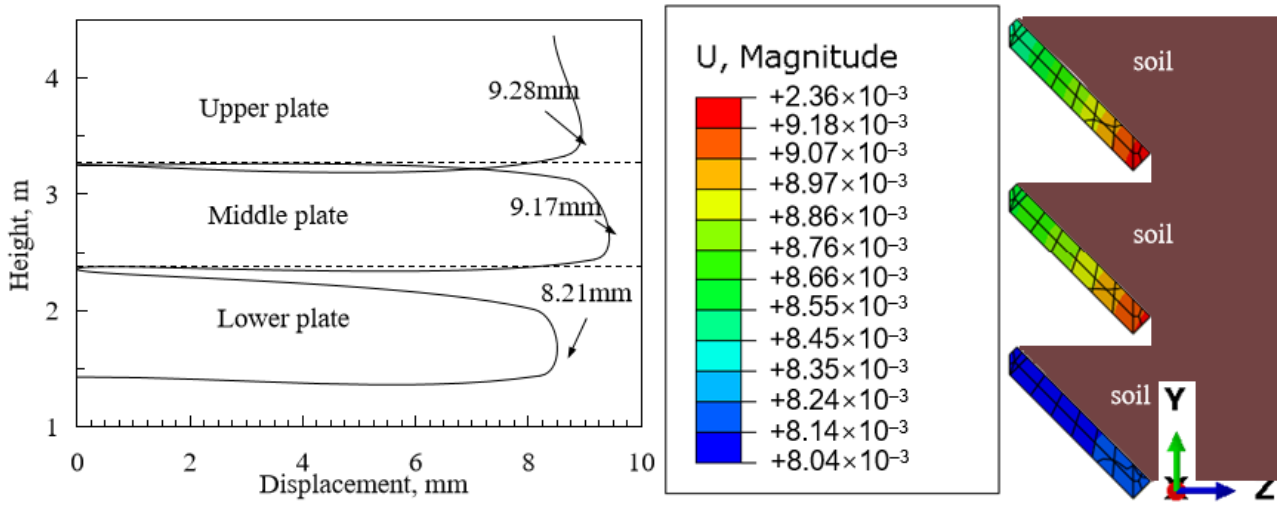

Figure 8. Displacement curve of inclined shelf with height.

The maximum principal stress (i.e., S, Max. Principal) distribution of each inclined shelf is shown in Figure 7. It should be noted that three inclined shelves are set on the retaining wall of the excavation section; the stress of the inclined shelf increases from bottom to top, and then decreases and alternates three times with U-shaped distribution, where each alternation represents the stress change of one inclined shelf. Peaks 1, 2, and 3 represent the maximum tension of the uppermost plate, the middle plate, and the lowermost plate, respectively. The stress values are 1.37 MPa (peak 1), 1.43 MPa (peak 2), and 1.12 MPa (peak 3), respectively. The stress between the middle plate and the upper plate increases by $4.4 \%$ and for the lower plate it is $21.7 \%$ less than for the middle plate. It can be observed that the stress growth rate is significantly less than the stress reduction rate from top to bottom. As shown in Figure 7, there is a gap between the plates where no structure can bear the earth pressure, causing a $0 \mathrm{kPa}$ stress value acting on the inclined shelf, and it finally leads to the formation of three sections of U-shaped lines. The U-shaped curve of the stress may be attributed to the triangular distributed earth pressure, which leads to the largest value of stress occurring at the bottom of each plate. Also observed is that the maximum stress occurred at the middle plate, which is located near the resultant point of earth pressure. The vertical dashed line represents the specification limits in Table 1 . Thus, the stress value of this structure does not exceed the specification limit under this working condition. 
Because the inclined shelf is deformed by soil pressure, it may be damaged when the deformation is too large. Thus, it is necessary to investigate its displacement. Similarly, since the inclined shelf can be approximately regarded as a simply supported beam structure under uniform load, it is feasible to obtain that the maximum displacement occurs between plates. As a result, the displacement between plates is taken as the standard of deformation of inclined shelf, with the results shown in Figure 8. In particular, the curve exhibits multi-section U-shaped distribution, which has three peaks. Each peak denotes the maximum displacement of each inclined shelf and each sudden decrease indicates the replacement of the plate. The formation of a multi-section U-shaped displacement curve is due to the replacement of plates from top to bottom. The displacement of each plate increases linearly from top to bottom. The displacement of the upper plate increases linearly from $8.45 \mathrm{~mm}$ to $9.28 \mathrm{~mm}$, indicating an increase of $9.8 \%$. Meanwhile, the displacement of the middle plate increases linearly from $8.63 \mathrm{~mm}$ to $9.17 \mathrm{~mm}$, indicating an increase of $6.3 \%$, and the displacement of the lower plate increased from $8.05 \mathrm{~mm}$ to $8.21 \mathrm{~mm}$, i.e., an increase of $2 \%$. The middle plate displacement is $1.1 \%$ smaller than the upper plate displacement, while the lower plate displacement is $10.5 \%$ smaller than the middle plate displacement. In general, the maximum displacement of the plate shall decrease as the height decreases.

\subsubsection{Stress Analysis of Anchor Rods}

The change of anchor rod stress along its length is shown in Figure 9. In particular, the $x$-axis runs along the length of the anchor rod and the $y$-axis corresponds to the equivalent stress of the anchor rod. With the increase in anchor length, the internal stress in the column has a small change. When passing through the column, the stress of the anchor rod changes suddenly and reaches the peak value. The peak stress of Anchor Rod 1 and 2 is $79.21 \mathrm{MPa}$ and $48.95 \mathrm{MPa}$, respectively. This is due to the large differences in the material properties of the column, leveling layer, and soil, and the relative slippage between the surfaces that causes uneven force acting on the anchor rod. The sliding surface lags behind as the result of the reinforcement effect of Anchor Rod 2, making the end area itself a sliding surface. It results in the stress at the end suddenly changing to $90 \mathrm{MPa}$ after entering the soil.

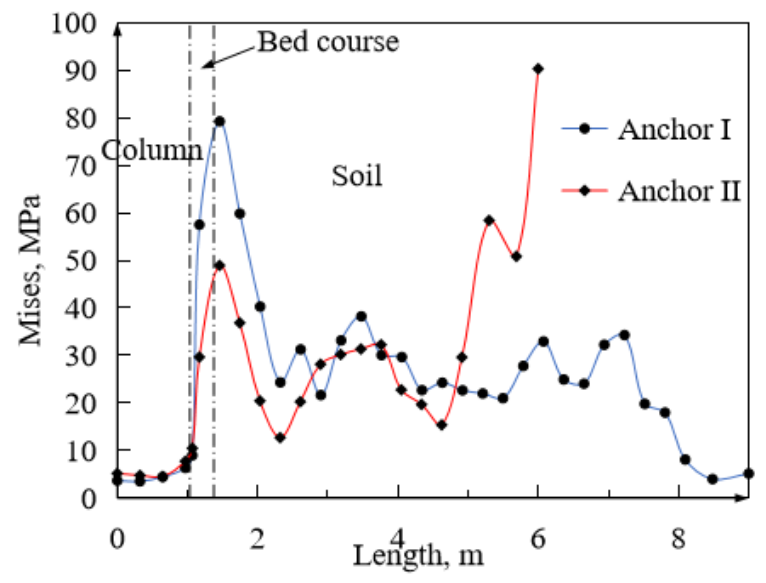

Figure 9. Stress distribution curve of anchor rod.

\subsection{Analysis of Influence of Anchor Rods on Side Slope Failure Mode}

To find the potentially most dangerous sliding surface, the strength reduction method is utilized and the effective plastic strain is obtained. Subsequently, the formation condition of the failure surface is validated [29,30]. Figure 10a shows the failure mode of the back slope with anchor rod support, while Figure $10 \mathrm{~b}$ shows the failure mode of the back slope without anchor rod support. In particular, the failure mode of this type of side slope is the overall sliding failure of the soil. The shape of the sliding surface is similar to an arc and the sliding surface passes through the end of the lower Anchor Rod 2. It can be 
observed by comparing Figure 10a,b that the sliding surface of the soil on the back of the column appears later than the inclined shelf. It is very straightforward to conclude that the reinforcement effect of the anchor rod makes the failure zone that penetrates the entire slope lag further behind. According to the failure mode of the prefabricated ecogrid retaining wall shown in Figure 10, the form of the sliding surface can be simplified as an arc with a radius of $9 \mathrm{~m}$ tangent to the column bottom.

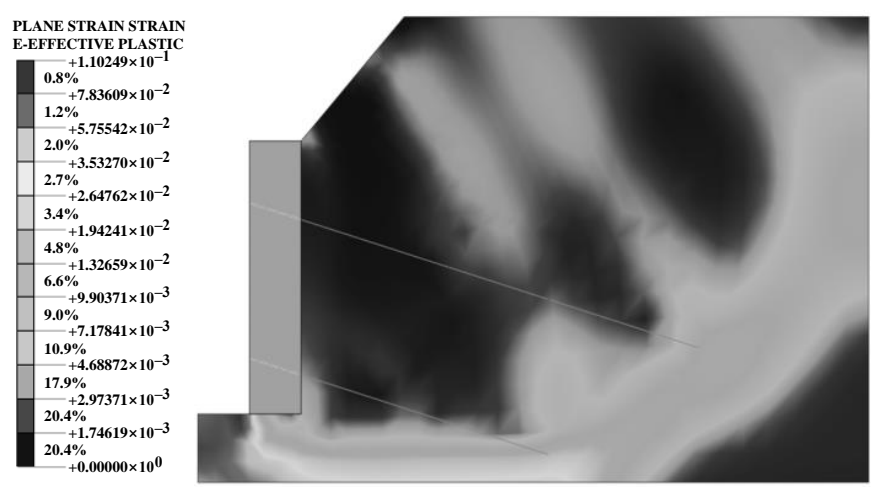

(a)

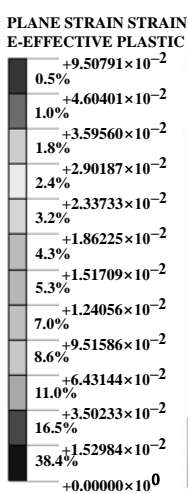

$+0.00000 \times 10^{0}$

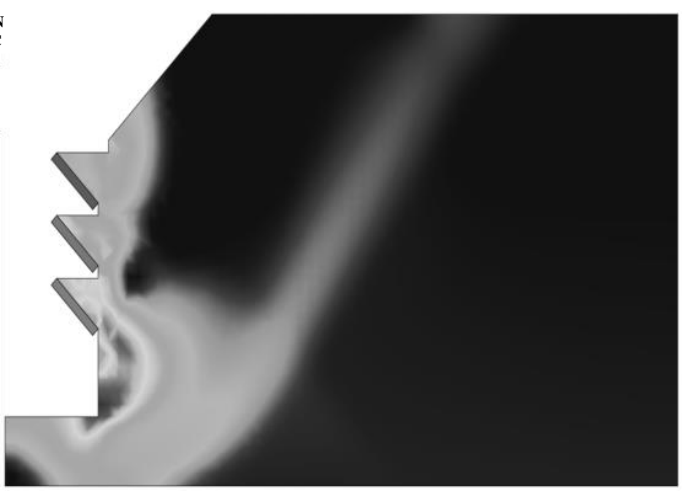

(b)

Figure 10. Soil failure mode: (a) Back soil for column; (b) Back soil for inclined shelf.

\subsection{Discussion of the Numerical Results}

The results obtained through the finite element analysis imply that the parts of the column and the inclined plate are subjected to large forces, which is critical to design. Therefore, it is necessary to carry out reinforced soil and anchoring treatment on the upper part of the slope. Meanwhile, the anchor rod may become excessively stressed at the contact position of the column and the soil if the traditional construction technology is used, so an anchor rod connector is utilized. By extending the anchor rod, in view of the fact that the force of the inclined plate and the column increase instantaneously due to the one-time placement of the inclined plate and the one-time filling, the crane and manual layered filling and layered placement of the inclined plate are utilized, which should eventually be planted with vegetation.

\section{Retaining wall Design and Mechanical Characteristics of Filling Section 4.1. Numerical Model \\ 4.1.1. Model Construction}

As demonstrated in Figure 11, the retaining wall is $5 \mathrm{~m}$ high in the actual project. In order to improve the hoisting efficiency, transportation convenience, and prefabrication degree, the upper and lower columns of the retaining wall are designed as $2.5 \mathrm{~m}$ high. For the purpose of enhancing the soil arching effect, the column net distance is $2 \mathrm{~m}$ and the columns support the prefabricated inclined shelves, whose upper parts are filled with soil for planting vegetation. Figure 11 shows the three-dimensional finite element model of the prefabricated ecological grid retaining wall. The three-side constraint of the soil is assumed to be a roller bearing type and the model adopts a structured meshing method. Columns, soil, anchor rods, inclined shelves, and leveling layers all use the eight-node hexahedral elements (C3D8). The contact surface of the inclined shelf and column adopts hard contact for normal contact and tangential contact adopts penalty. The internal reinforcement cage of the columns and the internal reinforcement mesh of the inclined insert plate are modeled by one-dimensional truss elements, embedded in the column and insert plate. 


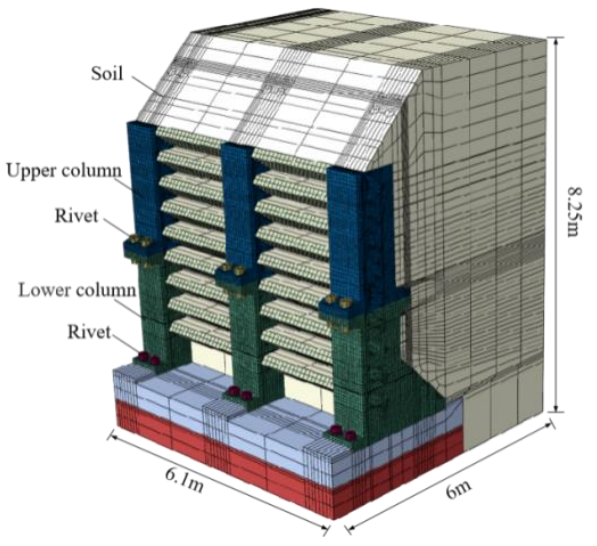

(a)

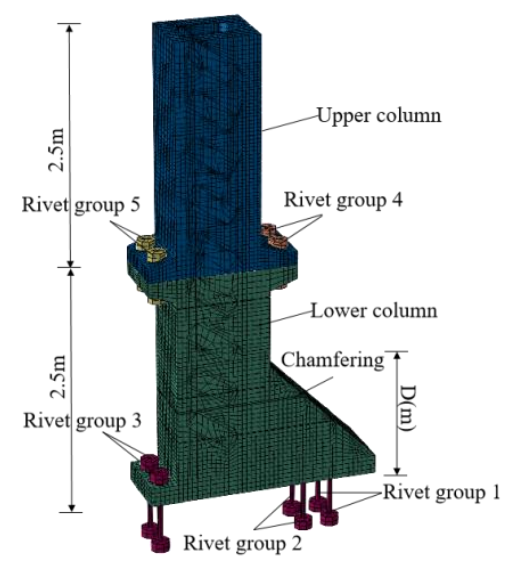

(b)

Figure 11. Meshing of prefabricated ecological grid retaining walls: (a) Overall meshing; (b) Column meshing.

\subsubsection{Parameter Selection}

The ABAQUS input parameters are shown in Table 1 in Section 3.1.2. Multiple studies have confirmed that the plastic damage model should be applied under monotonic loading [24-27], so the concrete plastic damage model is used in this section. The maximum principal stress is employed to determine whether brittle failure occurs, and the Tresca condition is used to determine whether shear failure occurs. The calculation is not convergent to prevent the soil from being damaged by shearing, so a concrete pavement is added to the top of the soil.

\subsection{Study of Equivalent Soil Thickness under Different Working Conditions \\ 4.2.1. Working Condition Cases}

Working Condition 1: No vehicle load on the upper part.

Working Condition 2: Vehicle load equivalent to $0.75 \mathrm{~m}$ of soil thickness. According to a standard [5] (Derucher et al., 1978), the vehicle load is equivalent to the uniform soil thickness, $h_{0}$, which is determined as follows:

$$
h_{0}=\frac{q}{\gamma}
$$

where $h_{0}$ represents the equivalent soil thickness, $\gamma$ represents the bulk density of the fill, and $q$ represents the standard value of additional vehicle load.

Working Condition 3: Numerical simulated vehicle load with the ABAQUS software.

Since the structural characteristics of prefabricated ecological grid retaining wall subjected to vehicle load are not well known in the literature, Working Condition 3 is investigated based on the numerical simulations. The numerical results are compared with Working Condition 2 in order to improve the design efficiency of such retaining walls in future applications. Moreover, this investigation may help to explore the applicability of this kind of retaining wall over the world according to the applicability of the design method.

The road surface is rolled according to the vehicle model specified in Derucher et al. [5], which is shown in Figure 12.

The vehicle vibration effect is mainly caused by the unevenness of the road surface, which can be expressed as follows:

$$
F(t)=p+p_{i} \sin ^{2} \frac{\pi t}{T}
$$

where $p$ represents the static load of the vehicle, $p_{i}$ represents the load caused by different wheels, and $T$ represents the load action period. 


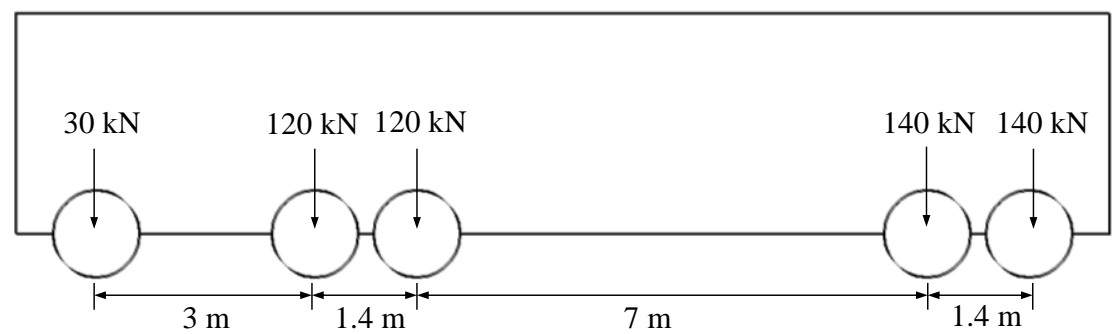

(a)

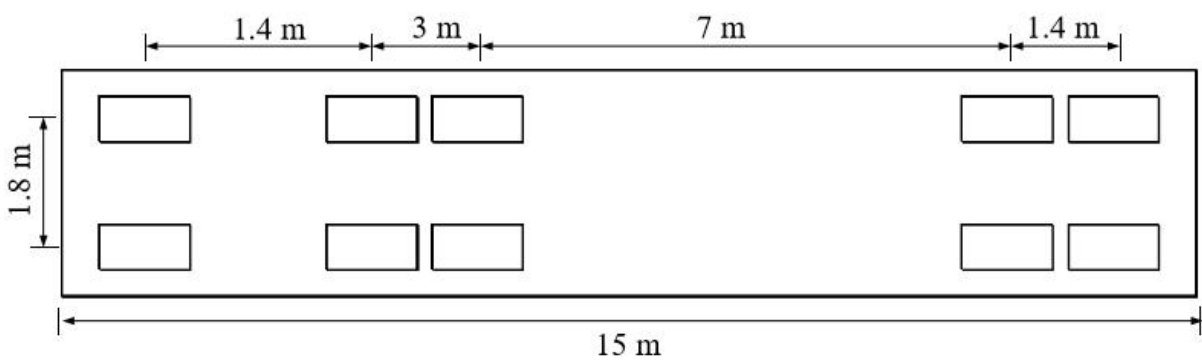

(b)

Figure 12. Vehicle dimensions: (a) Vehicle side view; (b) Bird's eye view.

Assuming that the contact surface between each wheel and the ground is rectangular, the front wheel rectangle is $0.3 \times 0.2 \mathrm{~m}$, while the middle and rear wheel rectangle can be simplified to $0.6 \times 0.2 \mathrm{~m}$, and each frame passes $0.3 \mathrm{~m}$. The simulation is divided into 7 stages. Stage I is the ground stress balance stage; in Stage II, the front wheels of the vehicle enter the retaining wall simulation area; in Stage III, the middle wheels do; in Stage IV, the rear wheels do, by which time all the wheels are acting on the retaining wall. In Stage V, the front wheels move out of the simulation area of the retaining wall; in Stage VI, the middle wheels do; in Stage VII the rear wheels do, with a total of 74 frames. The simulation of the retaining wall is now complete. Assuming $0.3 \mathrm{~m}$ per frame, we can write:

$$
F(t)=p+\sum p_{i} \sin ^{2} 209.44 t
$$

\subsubsection{Stress Analysis of Inclined Shelf in Different Working Conditions}

In order to study the stress on each plate, the plates are numbered 1-10 from top to bottom. Figure 13 shows how the tensile stress between the baffle plates changes with height, where the abscissa denotes the maximum tensile stress between the plates and the ordinate denotes the plate number. It can be observed that the maximum stress between the plates increases first and then decreases. The tensile stress of each plate in Working Conditions 2 and 3 is obviously greater than that in Working Condition 1. Moreover, the tensile stress between the plates in Working Condition 2 increases from $0.66 \mathrm{MPa}$ in Plate 1 to $0.82 \mathrm{MPa}$ in Plate 5 , an increase of $24 \%$. Then, it begins to decrease, and finally drops to $0.42 \mathrm{MPa}$, with a $49 \%$ reduction compared to the peak value. In Working Condition 3 , the tensile stress between plates increases from 0.64 MPa in Plate 1 to $0.84 \mathrm{MPa}$ in Plate 4, with an increase of $31.25 \%$. Then, it starts to decrease to $0.43 \mathrm{MPa}$, which is a $49 \%$ reduction compared to the peak value. The stress trend between Plate 5 and Plate 6 fluctuates slightly. This is because the two plates are respectively connected with the upper and lower columns and the contact surfaces exhibit relative slippage. According to the Yoo principle of unloading retaining wall [31], the sudden change of the cross-section of the column at the rivet joint plays only a minor role in unloading. The use of the numerical simulated vehicle load results in the maximum stress value between the plates being slightly larger than that of the equivalent soil thickness of $0.75 \mathrm{~m}$ specified in the standard [5]. 


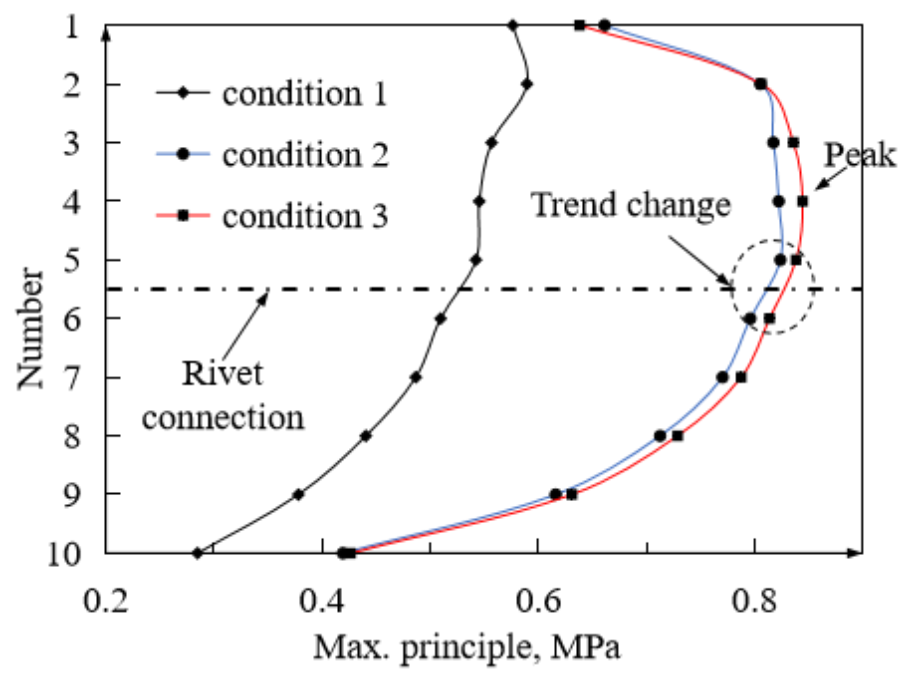

Figure 13. Maximum tensile stress between plates.

The change of the displacement between baffle plates with height is shown in Figure 14. In particular, the maximum distance between the plates is smaller as the result of small column net distance. It is quite straightforward to conclude that the overall trend of the displacement between the plates is to increase first and then decrease. Meanwhile, the displacement between the plates in Working Conditions 2 and 3 is greater than that in Working Condition 1. Due to the relative slip between the upper and lower columns and the unloading effect of the anchor rod connection, the displacement between Plates 4 and 8 varies with height. In addition, Working Condition 2 produces two peaks, which are located in Plates 4 and 7, with values of $0.22 \mathrm{~mm}$ and $0.216 \mathrm{~mm}$, respectively. Working Condition 3 is influenced by vehicle load and Plate 4 is at the soil arch foot. Thus, there are three peaks for Plates 4, 6, and 8 of $0.22 \mathrm{~mm}, 0.217 \mathrm{~mm}$, and $0.21 \mathrm{~mm}$, respectively. Consequently, the maximum displacement between the plates caused by the numerical simulated vehicle load is essentially consistent with the trend of the results produced by the equivalent $0.75 \mathrm{~m}$ of soil.

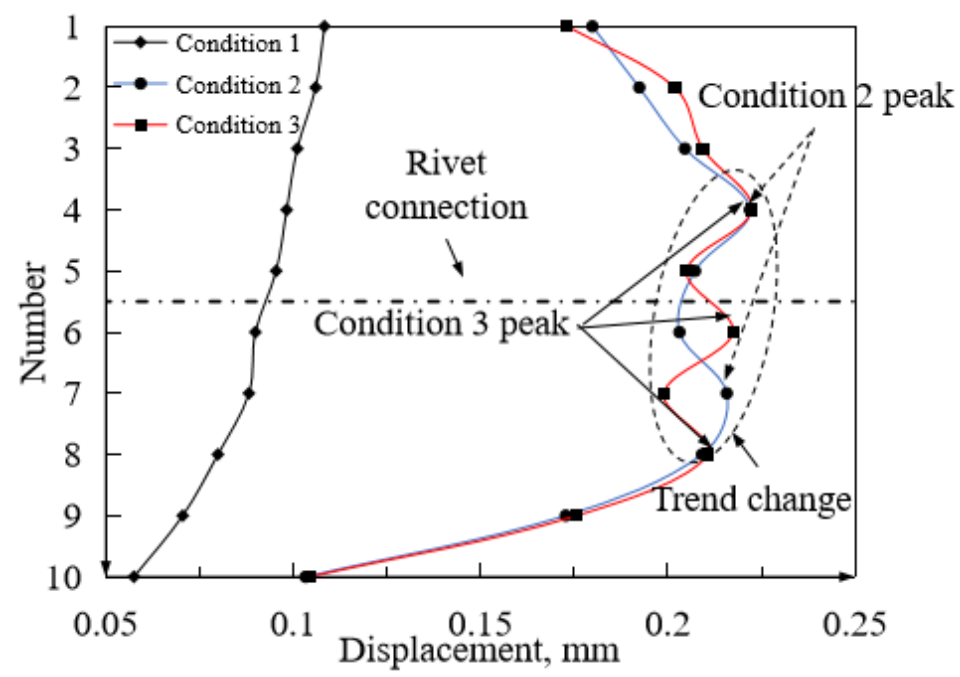

Figure 14. Maximum displacement between plates.

\subsubsection{Analysis of Column Stress in Different Working Conditions}

Figure 15a shows the change of the maximum principal stress of the column with height. In particular, the maximum principal stress of the lower column increases first and then decreases, reaching the peak in the chamfering zone as the result of the compression of 
the soil. Working Condition 3 has the largest stress peak in the chamfering zone, Working Condition 2 comes second, and Working Condition 1 comes last. It can be seen that the quarter-body two-degree-of-freedom vehicle model has a greater impact on the chamfer of this type of retaining wall. Due to the relative movement between the upper and lower columns, the stress changes at their junction. The maximum principal stress of the upper column is generated by the riveting head, and, except for the contact with the riveting head, the stress of the upper column gradually decreases along with the height, while the stress values are small. The stress distributions in the three working conditions are consistent.

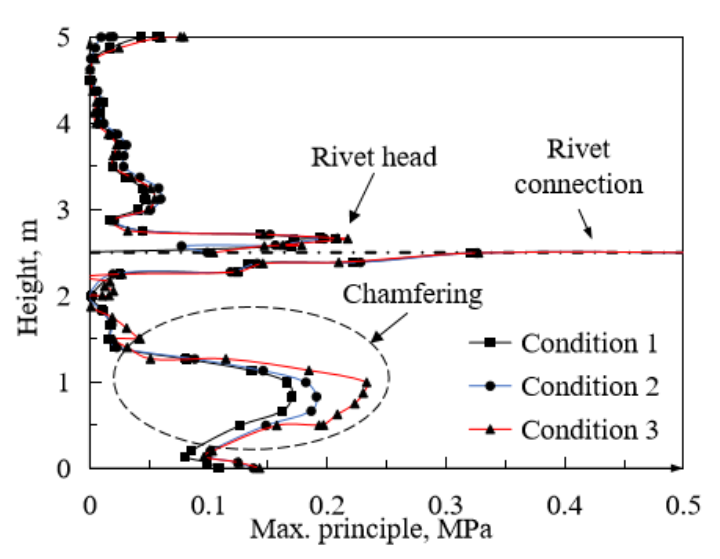

(a)

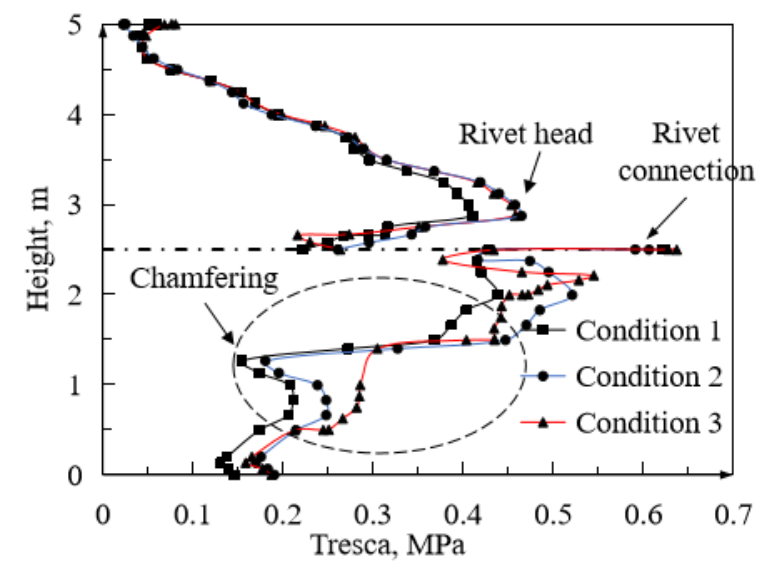

(b)

Figure 15. Column-back stress distribution: (a) maximum principal stress; (b) shear stress.

Figure $15 \mathrm{~b}$ shows the changes of vertical column shear stress along the column height. In particular, the shear stress of the lower column increases linearly with height, but it decreases suddenly when entering the chamfer zone. Moreover, the stress values of Working Condition 3 are larger, and the stress curves of Working Conditions 1 and 2 are consistent. A sudden change in stress occurs between the upper line columns as the result of the relative slippage of the upper and lower columns. The shear stress decreases linearly along the height of the upper column. Except for the rivet head, the three working conditions are consistent, indicating that this type of vehicle load has a certain impact on the contact between the rivet and the concrete part of the prefabricated ecological grid retaining wall.

The trend of column displacement with height is shown in Figure 16. It can be seen from the figure that the displacement values of the lower column are close in all three working conditions, and the magnitudes are in order of Working Condition 3, Working Condition 2, and Working Condition 1 . In addition, the upper and lower columns slip at the junction, thus, the curve has a breakpoint. The upper column deflection tends to increase with height in Working Conditions 2 and 3, while in Working Condition 1 it increases first and then decreases with the height. It is quite straightforward to conclude that the influence of the two-degree-of-freedom quarter-body vehicle model on the deflection of the prefabricated eco-grid retaining wall is greater than that of the standard equivalent $0.75 \mathrm{~m}$ thick soil layer, so the simulation method is more conservative than the standard [5]. 


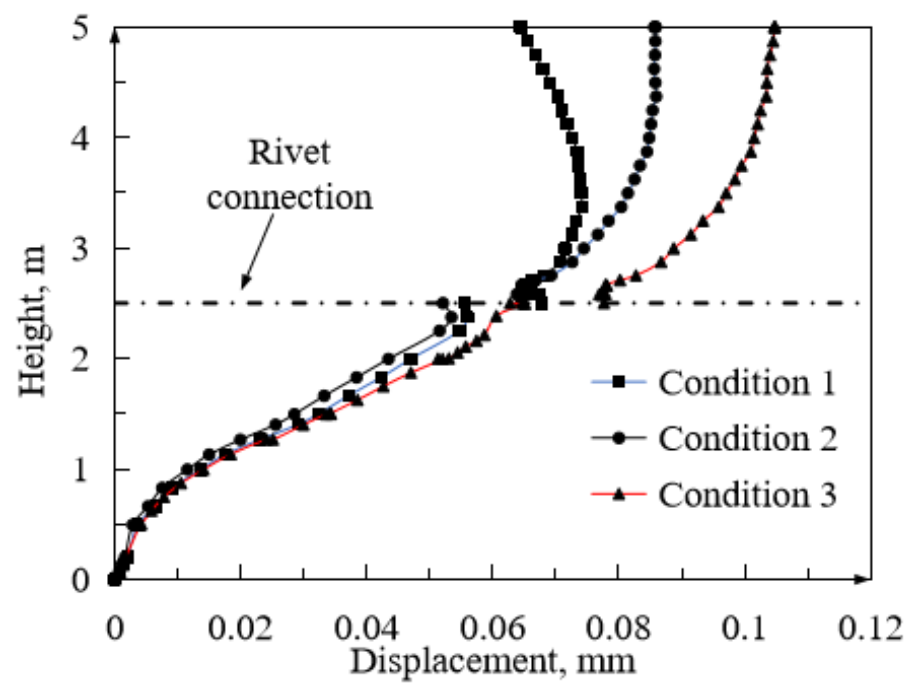

Figure 16. Column displacement-height curve.

\subsubsection{Stress Analysis of Rivets in Different Working Conditions}

The rivets are divided into 5 groups, with Rivet Groups 1, 2, and 3 directly driven into the lower rock mass by anchor rods in actual applications. Thus, only Rivet Groups 4 and 5 are analyzed.

The change of the stress of Rivet Groups 4 and 5 with the nail length is shown in Figure 17, where the curve is the maximum stress envelope of rivets at various heights. With the increase of nail length, the stress of rivet Group 4 first increases and then decreases. The stress of Rivet Group 5 first increases, then decreases, next, it again increases, and then decreases with the increase in nail length, showing a 3 shape. In the three working conditions, the anchor stress envelope diagrams are consistent. This is due to the small displacement of the column, which results in small rivet stress. Therefore, it can be concluded that the impact of vehicular dynamical load and equivalent soil thickness on rivets is the same.

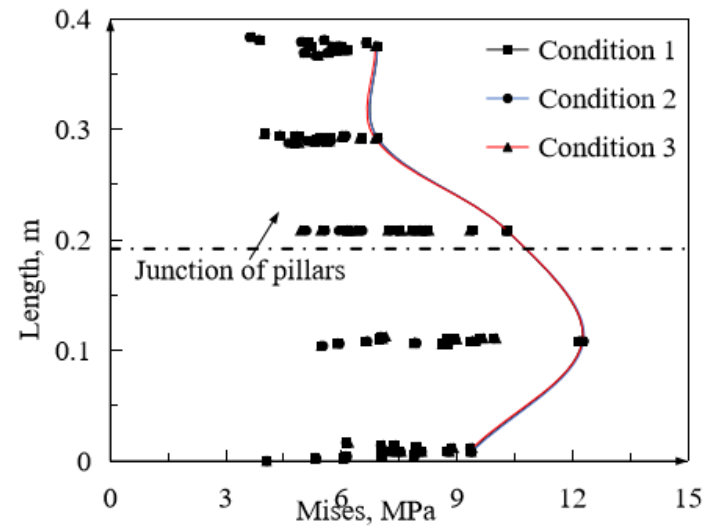

(a)

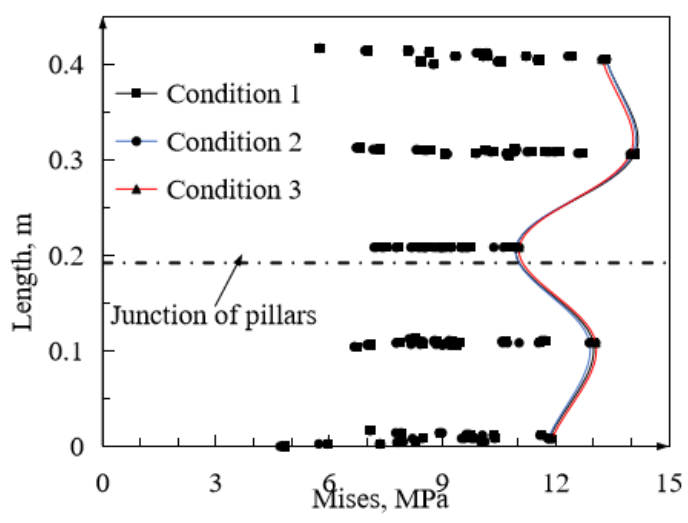

(b)

Figure 17. Rivet stress-nail length curve: (a) Rivet group 4; (b) Rivet group 5.

\subsubsection{Discussion on the Applicability of the Design Method}

The numerical simulation indicates that for the normal operating condition, the force on some areas of the retaining wall is too small (in some sections, the force may approximate to 0); the retaining wall column can therefore be designed as a hollow thin-wall structure to effectively reduce the cost. Due to the open type of the inclined shelf, vegetation can 
be planted on it to achieve the purpose of ecological environmental protection. This will integrate the retaining wall with the nature, improve driving comfort, and improve the drainage of the retaining wall, so as to avoid the defects of poor drainage and the effect of poor landscape of the traditional closed retaining wall structure. As a result, the prefabricated ecological grid retaining wall proposed in this paper has the advantages of a high degree of prefabrication, small lifting difficulty, convenient transportation, material saving, light weight, greening, good landscape effect, and good drainage, and can therefore can be extensively promoted and applied.

According to the adaptability of the design method, the following useful conclusions for practical engineering applications can be obtained from the above numerical simulations:

(1) As shown in Figures 13 and 14, the stress and displacement curves of condition 2 (result of design method) are basically consistent with that of condition 3 (numerical simulated vehicle load). As a result, the existing code can be used for the design and calculation of inclined shelf for the prefabricated ecological grid retaining wall proposed in this paper.

(2) Compared with condition 2 and condition 3, the stress condition is basically consistent, but the displacement for condition 3 is approximately $22 \%$ higher than that for condition 2, which may be attributed to the influence of vehicle dynamic load on the bolt. Since the displacement difference between the two conditions is too small, the design method can also be applied to the design and calculation of the column. However, for the anti-overturning calculation, the slip at the junction of upper and lower columns should be carefully checked to ensure the anti-overturning ability.

(3) The influence of different working conditions on the bolt can be ignored. In normal operating conditions, the stress is far less than the yield strength of the bolt (i.e., steel); the tapping steel bar can be directly used to replace the bolt for construction, so as to reduce the cost.

\subsection{Exploration of Displacement Mode}

It is necessary to judge the displacement mode of retaining wall to calculate and correct the earth pressure according to the design method. The retaining wall of the filling section is shown in Figure 18. For the rigid retaining wall, the wall displacement mode can be grouped into five types [32]. The displacement modes of different rigid retaining walls can be quantified using the following ratio:

$$
n=\frac{S_{u p}}{S_{\text {down }}}
$$

where $S_{\text {up }}$ and $S_{\text {down }}$ denote the displacement at top and bottom of the retaining wall and $\mathrm{n}$ denotes the judgment value describing the displacement mode of the retaining wall: when $n$ is 1 , the retaining wall is in T-mode; when $n$ is 0 , the retaining wall is in RT-mode; when $n$ is $\infty$, the retaining wall is in RB-mode; when $0<n<1$, the retaining wall is in RTT-mode; and when $1<n<\infty$, the retaining wall is in RBT-mode.

The lower column of the prefabricated ecological grid retaining wall is considered as a rigid body. According to the column displacement-height curve shown in Figure 18, it can be seen that the lower column moves around the bottom, which indicates the RB displacement mode. Meanwhile, the upper column rotates around the point at the bottom and is in the RTT displacement mode. 


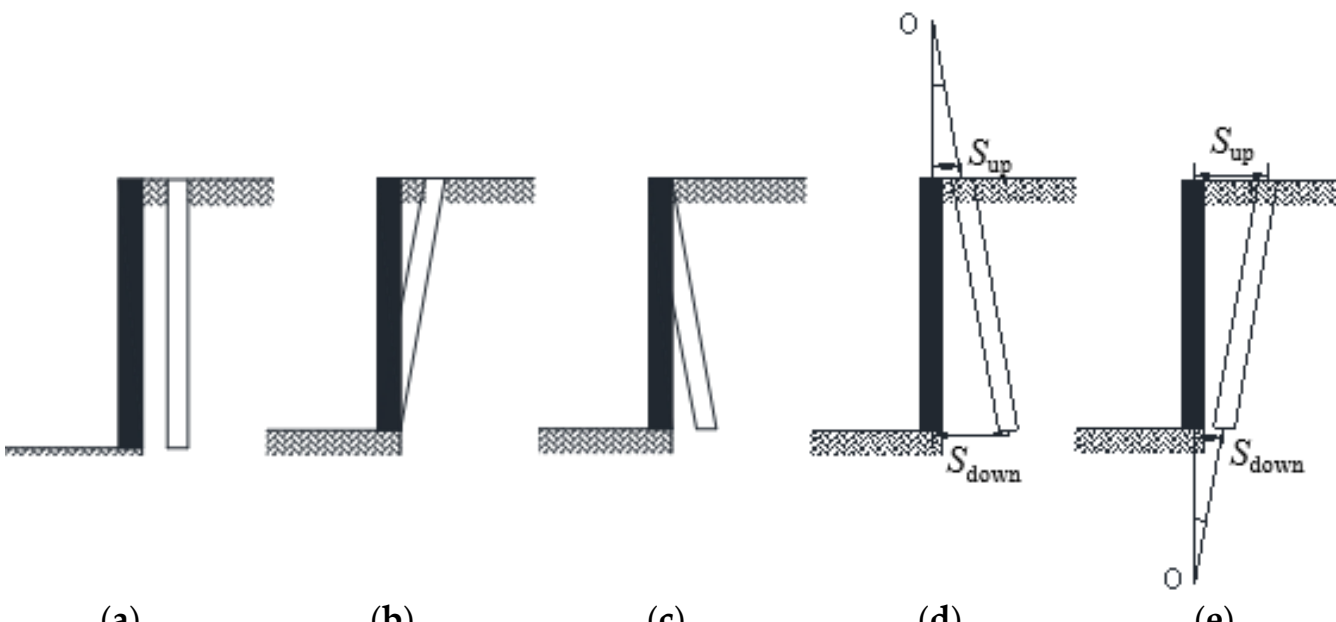

(a)

(b)

(c)

(d)

(e)

Figure 18. Retaining wall displacement modes: (a) T-mode: Moves horizontally; (b) RB-mode: Rotates around the bottom; (c) RT-mode: Rotates around the top; (d) RBT-mode: Rotates around one point at the top; (e) RTT-mode: Rotates around one point at the bottom.

\section{Conclusions}

Using the example of a retaining wall project in the Hangjinqu-Linpu Expressway, a three-dimensional numerical analysis of the prefabricated ecological grid retaining wall was carried out utilizing ABAQUS. Due to the asymmetrical condition of the project, the designed prefabricated ecological grid retaining wall was divided into the excavation section and the filling section. The failure modes of the prefabricated ecological grid retaining wall in the excavation section, the stress and displacement distributions of the column with height, the axial stress of the anchor rod, and the displacement of the inclined shelf were discussed. In addition, the column stress, deformation, rivet stress, distributions, and the displacement distribution of the inclined shelf in three working conditions of the prefabricated ecological grid retaining wall in the filling section were compared and discussed. The following main conclusions have been drawn:

(1) The stress and deformation trends of the inclined shelf exhibited repeated U-shaped changes. The maximum stress between the plates increases first and then decreases from top to bottom. The shape is similar to the soil arching effect between the piles, but the size is different.

(2) The stress of the excavation section column at the crossing position of the anchor rod changes significantly, reaching the maximum peak value. Meanwhile, the general trend of the stress changing with the column height has an M-shape. In similar projects, it is necessary to focus on monitoring the crossing of the anchor rod. The displacement of the entire column is small, and the lateral displacement of the column changes slowly within the range of the anchor rod constraint. Moreover, the lateral displacement of the column increases rapidly and reaches a peak after the anchor rod is lost. In similar projects, it is necessary to focus on monitoring the non-anchored area of the column. When the excavation section anchor rod passes through the leveling layer, the anchor rod stress begins to change suddenly, reaching a peak value at the junction of the leveling layer and the soil.

(3) The filling section column is formed by splicing upper and lower columns and the stress at the junction fluctuates along with the height. The displacement mode of the combined column is the RB-mode for the lower columns and the RBT-mode for the upper columns. The prefabricated ecological grid retaining wall proposed in this paper has applicability in the existing design method, specifically in the inclined shelf, column, and bolt in Working Conditions 2 and 3 which are basically consistent, so the 
particularity of the structure itself can be ignored; the design and calculation can be carried out according to the design method.

(4) As indicated by the numerical results, the prefabricated ecological grid retaining wall proposed in this paper has the advantages of a high degree of prefabrication, small lifting difficulty, convenient transportation, material saving, light weight, greening, and good landscape effect, and can therefore can be extensively promoted and applied over the world.

Author Contributions: Conceptualization, methodology, software, validation, and original draft preparation, C.Z.; data curation, Y.N.; guidance, review, and revision, H.D.; translation, editing, and review, X.W. All authors have read and agreed to the published version of the manuscript.

Funding: The Natural Science Foundation of China (52009122); Zhejiang Provincial Natural Science Foundation of China (LQ21E090002); Science and technology project supported by the Department of transportation of Zhejiang Province (2019007); General Research Project supported by the Department of Education of Zhejiang Province (Y201941345) is acknowledged.

Institutional Review Board Statement: Not applicable.

Informed Consent Statement: Not applicable.

Data Availability Statement: Not applicable.

Conflicts of Interest: The authors declare no conflict of interest.

\section{References}

1. Xie, M.; Zheng, J.; Zhang, R.; Cui, L.; Miao, C. Performance of a Combined Retaining Wall Structure Supporting a High Embankment on a Steep Slope: Case Study. Int. J. Géoméch. 2020, 20, 05020002. [CrossRef]

2. Nakazawa, H.; Usukura, K.; Hara, T.; Suetsugu, D.; Kuribayashi, K.; Nishi, T.; Kimura, S.; Shimomura, S. Problems in Earthquake Resistance Evaluation of Gabion Retaining Wall Based on Shake Table Test with Full-Scale Model. J. Disaster Res. 2019, 14, 1154-1169. [CrossRef]

3. Yu, Y.; Bathurst, R.J.; Allen, T.M.; Nelson, R. Physical and numerical modelling of a geogrid-reinforced incremental concrete panel retaining wall. Can. Geotech. J. 2016, 53, 1883-1901. [CrossRef]

4. Wang, H.; Yang, G.; Wang, Z.; Liu, W. Static structural behavior of geogrid reinforced soil retaining walls with a deformation buffer zone. Geotext. Geomembranes 2020, 48, 374-379. [CrossRef]

5. Derucher, K.; Schelling, D.; Patel, V. Methods and practice in cantilever retaining wall design. Comput. Struct. 1978, 8, 569-582. [CrossRef]

6. Ortiz, L.A.; Scott, R.F.; Lee, J. Dynamic centrifuge testing of a cantilever retaining wall. Earthq. Eng. Struct. Dyn. 1983, 11, 251-268. [CrossRef]

7. Rabie, M. Performance of hybrid MSE/Soil Nail walls using numerical analysis and limit equilibrium approaches. HBRC J. 2016, 12, 63-70. [CrossRef]

8. Deshmukh, V.B.; Dewaikar, D.M.; Choudhary, D. Uplift Capacity of Horizontal Strip Anchors in Cohesionless Soil. Geotech. Geol. Eng. 2011, 29, 977-988. [CrossRef]

9. Yuan, J.; Lin, P.; Huang, R.; Que, Y. Statistical evaluation and calibration of two methods for predicting nail loads of soil nail walls in China. Comput. Geotech. 2019, 108, 269-279. [CrossRef]

10. Day, R.; Potts, D. Modelling sheet pile retaining walls. Comput. Geotech. 1993, 15, 125-143. [CrossRef]

11. Farhat, M.; Issa, M.; Ibrahim, M.; Rahman, M. Full-Scale Experimental Testing and Finite Element Analysis of a Totally Prefabricated Counterfort Retaining Wall System. PCI J. 2017, 62, 72-88. [CrossRef]

12. Rao, P.; Chen, Q.; Zhou, Y.; Nimbalkar, S.; Chiaro, G. Determination of Active Earth Pressure on Rigid Retaining Wall Considering Arching Effect in Cohesive Backfill Soil. Int. J. Géoméch. 2016, 16, 04015082. [CrossRef]

13. Terzaghi, K. Theoretical Soil Mechanics; Wiley: New York, NY, USA, 1943.

14. Wang, M.-M.; Wu, S.-G.; Wang, G.-L. Limit analysis method for active earth pressure on laggings between stabilizing piles. J. Mt. Sci. 2017, 14, 196-204. [CrossRef]

15. He, Y.; Hazarika, H.; Yasufuku, N.; Teng, J.; Jiang, Z.; Han, Z. Estimation of lateral force acting on piles to stabilize landslides. Nat. Hazards 2015, 79, 1981-2003. [CrossRef]

16. Wu, J.; Li, C.; Liu, Q.; Fan, F. Optimal isosceles trapezoid cross section of laterally loaded piles based on friction soil arching. KSCE J. Civ. Eng. 2017, 21, 2655-2664. [CrossRef]

17. Zevgolis, I.E. A Finite Element Investigation on Displacements of Reinforced Soil Walls Under the Effect of Typical Traffic Loads. Transp. Infrastruct. Geotechnol. 2018, 5, 231-249. [CrossRef] 
18. Kaveh, A.; Khayatazad, M. Optimal design of cantilever retaining walls using ray optimization method. Iran. J. Sci. Technol.-Trans. Civ. Eng. 2014, 38, 261-274.

19. Lin, Y.-L.; Cheng, X.-M.; Yang, G.-L.; Li, Y. Seismic response of a sheet-pile wall with anchoring frame beam by numerical simulation and shaking table test. Soil Dyn. Earthq. Eng. 2018, 115, 352-364. [CrossRef]

20. JTG D60-2015. General Code for Design of Highway Bridges and Culverts; China Communications Press: Beijing, China, 2015.

21. Xu, C.; Xu, Y.; Sun, H.; Chen, Q. Characteristics of Braced Excavation under Asymmetrical Loads. Math. Probl. Eng. 2013, 2013, 1-12. [CrossRef]

22. Guo, P.P.; Gong, X.N.; Wang, Y.X. Displacement and force analyses of braced structure of deep excavation considering unsymmetrical surcharge effect. Comput. Geotech. 2019, 113, 103102. [CrossRef]

23. Ou, X.; Zhang, X.M.; Fu, J.Y.; Zhang, C.; Feng, H. Cause investigation of large deformation of a deep excavation sup-port system subjected to unsymmetrical surface loading. Eng. Fail. Anal. 2020, 107, 104202. [CrossRef]

24. Mitra, N.; Lowes, L.N. Evaluation, Calibration, and Verification of a Reinforced Concrete Beam-Column Joint Model. J. Struct. Eng. 2007, 133, 105-120. [CrossRef]

25. Wang, H.; Li, Y.; Li, S.; Zhang, Q.; Liu, J. An elasto-plastic damage constitutive model for jointed rock mass with an application. Géoméch. Eng. 2016, 11, 77-94. [CrossRef]

26. Poliotti, M.; Bairán, J.-M. A new concrete plastic-damage model with an evolutive dilatancy parameter. Eng. Struct. 2019, 189, 541-549. [CrossRef]

27. Sancak, E.; Cinicioglu, O. Selection of design friction angle: A strain based empirical method for coarse grained soils. Geomech. Eng. 2020, 20, 121-129. [CrossRef]

28. GB50010-2010. Code for Design of Concrete Structures; China Architecture and Building Press: Beijing, China, 2010.

29. Bonilla-Sierra, V.; Scholtes, L.; Donzé, F.V.; Elmouttie, M.K. Rock slope stability analysis using photogrammetric data and DFN-DEM modelling. Acta Geotech. 2015, 10, 497-511. [CrossRef]

30. Ma, J.Z.; Zhang, J.; Huang, H.W.; Zhang, L.L.; Huang, J.S. Identification of representative slip surfaces for reliability analysis of soil slopes based on shear strength reduction. Comput. Geotech. 2017, 85, 199-206. [CrossRef]

31. Yoo, W.-K.; Kim, B.-I.; Moon, I.-J.; Park, Y.-S. Comparison of the Lateral Earth Pressure on the Retaining Wall with the Relieving Platform by Model test and Numerical Analysis. J. Korea Acad. Coop. Soc. 2012, 13, 2382-2389. [CrossRef]

32. Peng, S.-Q.; Li, X.-B.; Fan, L.; Liu, A.-H. A general method to calculate passive earth pressure on rigid retaining wall for all displacement modes. Trans. Nonferrous Met. Soc. China 2012, 22, 1526-1532. [CrossRef] 